\title{
Narrativas de sofrimento e trabalho profissional do Serviço Social da Previdência Social em tempos de indústria $4.0^{*}$
}

\section{Narratives of Suffering and Professional Work of Social Workers in Social Security in the Industrial times 4.0}

\author{
Edvânia Ângela de Souza ${ }^{a}$ \\ (1) https://orcid.org/0000-0002-8997-7592 \\ Luís Anunciaçãob \\ (D) https://orcid.org/0000-0001-5303-5782
}

\begin{abstract}
Resumo: Atuais mudanças econômicas, sociais e políticas geram impactos nos ambientes e nas condições psicossociais de trabalho. Neste texto, discute-se o trabalho de Assistentes Sociais (AS) atuantes na Previdência Social (PS), a partir da combinação de resultados obtidos por meio de projeto de pesquisa em andamento, cuja metodologia faz uso de escalas padronizadas, grupos focais e entrevistas realizadas entre 2014 e 2019. Apesar de não haver resultados negativos obtidos pelos instrumentos padronizados, as outras técnicas puderam revelar que o trabalho gera um tipo de sofrimento mudo, invisível e marcado pela angústia e frustração.

Palavras-chave: Indústria 4.0 ou $4^{\text {a }}$ Revolução Industrial (4a RI). Seguridade Social. Serviço Social. Sofrimento no trabalho.
\end{abstract}

\begin{abstract}
The current economic, social, and political changes have impacts on the work environment and the psychosocial conditions of the workers. In this study, we discuss the professional work of Social Workers (SW) working in working in the Brazilian social security system, using a mixed-methods approach including the results obtained through standardized scales, focus groups, and interviews conducted between 2014 and 2019. Despite the results obtained by psychometric systems suggest a non-negative outcome, the other methods could reveal that work generates a kind of silent, invisibility and is marked by distress and/or suffer.
\end{abstract}

Keywords: Industry 4.0 or 4 th Industrial Revolution (4th RI). Social Security. Social Work. Work distress.

*Registra-se um agradecimento especial a todas e todos assistentes sociais que participaram direta ou indiretamente deste estudo, sem essa colaboração e participação não teria sido possível o desenvolvimento do presente projeto e respectiva reflexão.

aniversidade Estadual Paulista Júlio de Mesquita Filho - UNESP, Franca/São Paulo, Brasil.

'Pontifícia Universidade Católica — PUC-Rio, Rio de Janeiro/RJ, Brasil.

Recebido: 4/10/2019 - Aprovado: 21/2/2020 


\section{Introdução}

tualmente, o avanço das tecnologias da informação, microele-
trônica e robótica têm acentuado a subordinação da força de
trabalho a aspectos puramente financeiros. Entende-se que estamos vivenciando um cenário que admite condições absolutamente inseguras do trabalho e da totalidade da vida social. Nas palavras de Antunes (2018), o irracionalismo fetichizado de nosso tempo impõe um mundo do trabalho informal e precário. Consequentemente, isso gera um trabalho marcado pela uberização, walmarterização, intermitência e pejotização, cujas relações são desprotegidas e eivadas da ideologia do empreendedorismo, da suposta autonomia e do individualismo.

Mesmo que grupos de economistas e políticos repitam que no lugar das ocupações que se encerram em função das mudanças tecnológicas muitas outras surgirão, tanto a análise retrospectiva das mudanças do mundo do trabalho quanto o exame atual indica que a redução da força de trabalho vivo poderá chegar a níveis inimagináveis. Assim, é preciso encarar que a iminência da $4^{\text {a }}$ Revolução Industrial (4 $4^{\text {a }}$ I ou Indústria 4.0) é um momento de agudização da modernização capitalista, diga-se de passagem, altamente financeirizada e informacional.

Schwab (2016) informa que a revolução tecnológica em curso, com a profusão de numerosas áreas, tais como: inteligência artificial (IA); robótica, a internet das coisas (IoT, na sigla em inglês), veículos autônomos, impressão 3-D, nanotecnologia, biotecnologia, ciência dos materiais, armazenamento de energia e computação quântica, Big Data, entre outros, implicará a transformação de toda humanidade. Sustenta o autor que a sua análise diverge dos estudos que apontam que as mudanças em curso são tão somente uma extensão da 3a Revolução Industrial (3a RI). Para Schwab (2016), caracteriza-se em $4^{\text {a }}$ RI devido à velocidade com que as mudanças e inovações ocorrem e, ainda, à capacidade de ampliação de cada descoberta que se aprofunda em outra e outra, como um efeito dominó. Schwab sublinha também que se trata de uma revolução devido à fusão das tecnologias do mundo físico, digital e biológico e, por fim, o 
autor indica o impacto sistêmico sobre o trabalho e a vida socioambiental. Aqui, cabe ressaltar o possível desemprego em níveis inimagináveis.

A luta da classe trabalhadora para colocar limites à exploração desenfreada do capital sobre o trabalho elevou os níveis de civilidade. Ainda que a história seja marcada pelo desrespeito à legislação trabalhista e previdenciária, essa representou um grau de proteção social, contudo incompleto no Brasil, uma vez que persistiu o trabalho informal, infantil e até mesmo análogo à escravidão. Entretanto, não se pode desconsiderar que níveis civilizatórios também foram estabelecidos como horizonte a partir da regulação do trabalho e da garantia de direitos sociais e previdenciários.

Todavia, é imperativo afirmar que está em marcha um movimento de restrição dos direitos sociais, do trabalho e previdenciários, acompanhado do desemprego exponencial e acentuada precarização do trabalho. Os avanços da ciência e da tecnologia apropriados privadamente pelo capital resultam num falso consenso, no qual a linha mestra é que a geração de empregos apareça à sociedade como se fosse um favor do capital: "[...] afinal, ele não precisa mais de gente, são as pessoas que precisam da sua boa vontade" (Viana, 2012, p. 52). Assim, os que conseguirem trabalho o farão a partir de contratos mais flexíveis, desprovidos de garantias trabalhistas e mais sujeitos à intensificação do trabalho, ainda que aparentemente isso seja visto como autonomia e liberdade.

Por essa razão, parte-se do pressuposto de que o trabalho do(a) assistente social (AS) desenvolvido no interior de processos de trabalho, no caso aqui tratado, na Previdência Social (PS), enquanto uma das áreas que compõe a Seguridade Social, sofre no seu cotidiano com as imposições concretas da busca de renovação das taxas de acumulação do capital, tal como garante a contrarreforma do Estado, incluindo a contrarreforma da PS e a captura do Fundo Público pelo capital, na sua dinâmica financeirizada.

O projeto em curso do atual governo de Jair Bolsonaro, como sua proposta de Emenda Constitucional $n^{\circ}$ 06/2019, que restringe a PS a uma parcela muito pequena de trabalhadores(as) e empurra toda a sociedade 
para a tal da nova Previdência (Lenzi, 2019), afeta principalmente idosos pobres, que ganham até dois salários mínimos, deficientes, agricultura familiar, trabalhadores(as) rurais e funcionários públicos, sendo que o que não foi aprovado já de imediato poderá sê-lo a qualquer momento, uma vez que muitas restrições apresentadas, até então garantidas como direitos constitucionais, passaram para Lei Complementar (LC), o que permite ao governo efetuar mudanças com muito mais celeridade que uma Emenda à Constituição (EC) (Souza, 2019).

Enquanto para o conjunto de trabalhadores(as) Jair Bolsonaro impôs uma série de limites para o acesso às aposentadorias e benefícios, ao agronegócio foi bastante generoso, inclusive garantiu a isenção de contribuição para a Seguridade Social sobre as suas exportações, sem falar que persiste na anistia aos grandes devedores da Previdência, com destaque para as empresas do agronegócio e grandes bancos. Os militares também receberam tratamento especial. Até o momento, não há nenhuma intenção de cobrar impostos sobre o mercado da fé (igrejas) ou de cobrar os devedores da Previdência, já indicados pelo Ministério da Economia como alta chance de recebimento. Os alvos fáceis são mesmos os pobres, inclusive impôs rigidez para as reavaliações dos benefícios previdenciários, por meio da Medida Provisória n. 871 (Brasil, 2019a), recentemente transformada em lei para a permanente avaliação de trabalhadores(as) em afastamentos, com intenção e êxito de suspensão (cortes) desses (Souza, 2019).

Para a aprovação da contrarreforma da PS, o governo Jair Bolsonaro disseminou um suposto déficit previdenciário. Todavia, ao contrário do que era de se esperar, no lugar de promover formas de financiamento da PS, recentemente, para atender demandas da elite empresarial, instituiu a Medida Provisória n. 905, de 11 de novembro de 2019, que instituiu a Carteira Verde Amarela, promovendo, de uma tacada só, a radical restrição dos direitos trabalhistas e previdenciários. Assim, diminuiu a contribuição previdenciária, tal como prevê o artigo 7, da Medida Provisória n. 905, que diz: "No Contrato de Trabalho Verde e Amarelo, a alíquota mensal relativa à contribuição devida para o FGTS de que trata o art. 15 
da Lei $n^{\circ} 8.036$, de 1990, será de dois por cento, independentemente do valor da remuneração" (Brasil, 2019b).

A partir do exposto, o presente trabalho possui como chave analítica o consumo da força de trabalho, como uma importante categoria pertencente ao campo da Saúde do Trabalhador (ST), com raiz da Saúde Coletiva, com o objetivo específico de descrever e discutir o trabalho profissional de Assistentes Sociais (AS) que trabalham na Previdência Social (PS) no Brasil, bem como as informações acerca das suas condições materiais de trabalho, relações sociais e as repercussões psicossociais do trabalho para a saúde e a satisfação no trabalho.

\section{Método}

A presente reflexão faz parte de um estudo mais amplo ${ }^{1}$, com o uso da abordagem quanti-qualitativa, a partir de entrevistas individuais, coletivas e grupos focais com AS das três áreas da Seguridade Social, bem como utiliza um questionário desenvolvido para avaliar tanto particularidades do perfil profissional como aspectos fundamentais das condições e organização do trabalho. Todas as técnicas de coletas de dados visam explorar o quanto os resultados obtidos podem gerar inferências para a saúde.

\footnotetext{
Este texto é parte fundamental do projeto de pesquisa: "Processo de trabalho e saúde dos e das assistentes sociais que atuam nos serviços de Seguridade Social no Brasil”, o qual foi aprovado pelo Comitê de Ética e Pesquisa da Unesp-Franca. Conta com a participação de pesquisadores(as) de três universidades públicas: Faculdade de Ciências Humanas e Sociais (Unesp-Franca), Universidade Federal do Pará (UFPA) e Universidade Federal do Rio Grande do Sul (UFRGS), sendo as respectivas coordenadoras de cada região as profas. dras. Edvânia Ângela de Souza (Unesp-Franca), Vera Gomes e Daniela Castilho (UFPA), Jussara Mendes, Dolores Sanches Wünsch e Tatiana Reidel (UFRGS). Esse projeto também fez parte das atividades de pós-doutorado, desenvolvido no período de 2015 a 2017 no Programa de Pós-Graduação em Saúde Coletiva da Unifesp, sob a supervisão do prof. dr. Francisco Antonio de Castro Lacaz, quando o projeto de pesquisa também foi aprovado pelo Comitê de Ética da Unifesp e submetido e aprovado pelo CNPq, conforme Processo n. 445443/2015-4, 2015-7. Atualmente, foi submetido e aprovado na modalidade Bolsa Produtividade (PQ) e aprovado sob o n. 313708/2018.
} 
Por ser tratar de um recorte de uma pesquisa mais ampla, outros resultados já se encontram publicados (Lourenço; Lacaz; Goulart, 2017; Lourenço et al., 2019 e Souza; Silva, 2019). Neste texto, a análise dos dados está restrita à PS, considerando o período de junho de 2014 a março de 2019. Pela abrangência metodológica, todas as análises são extensas e associadas às diferentes técnicas utilizadas.

Os dados empíricos são resultantes de autoaplicação dos questionários e entrevistas realizadas com AS que atuam na PS, especificamente: uma entrevista coletiva com duas AS que atuam em uma Agência da PS; dois grupos focais (GF) com AS de duas gerências da PS. ${ }^{2}$ Além dessas, foram realizadas quatro oficinas com AS em quatro gerências, com uma média de vinte AS em cada uma dessas oficinas. ${ }^{3}$ A coleta de dados livres se restringiu às cidades do interior do estado de São Paulo e do estado de Minas Gerais. Para garantia de sigilo e anonimato, utilizar-se-á a letra "X" para substituir nomes de cidades que porventura compareçam durantes as entrevistas. Omitem-se também os nomes dos(as) participantes.

No período de 2014 até março de 2019 foram respondidos 1.195 questionários. Desse total, 181 se referem a AS que atuam na PS.

Para esta discussão, foram selecionados dados estatísticos dos questionários referentes ao perfil sociodemográfico e as repercussões psicossociais do trabalho, com enfoque para as relações trabalho-saúde, a partir da escala "Bem-estar laboral geral", também utilizada de forma parcial, pela adoção das subescalas “Afetos e de competências” (Blanch et al. 2010; Goulart et al., 2012), como já explicitado em estudo anterior (Lourenço et al., 2019).

2 Explicita-se que a agência é um posto da Previdência Social (APS) localizado em determinado município, que está subordinada imediatamente a uma gerência regional da Previdência, sendo essa também uma agência, mas que congrega outras do seu território a título de gerenciamento.

3 As oficinas ocorreram durante o desenvolvimento de atividades do projeto de extensão universitária "O trabalho do Serviço Social no INSS e a saúde do trabalhador", desenvolvido no período de 2014 e 2015, com apoio da Proex, Unesp. 
Para as análises estatísticas dos instrumentos, inicialmente, a base de dados foi verificada para detecção de possíveis inconsistências e dados anômalos. Pela quantidade baixa de missings cases $(<5 \%)$ e pela alta consistência interna (Alfa de Cronbach padronizado $=0.92$ na escala de afetos e 0.95 na escala de competências), nenhuma técnica de imputação foi realizada. As variáveis que compõem os instrumentos padronizados foram apresentadas por médias (M), desvios-padrão (DP) e valores totais. Os itens do questionário de saúde foram calculados pelas proporções de presença/ausência. Para medir a consistência interna das escalas, o Coeficiente Alfa de Cronbach foi implementado. Análises correlacionais foram exploradas a partir do Coeficiente Produto-Momento de Pearson, enquanto modelos lineares para variáveis independentes categóricas (Anova de uma via) foram construídos para investigar os possíveis efeitos de fatores sociodemográficos nos resultados obtidos. Optou-se pela utilização de técnicas paramétricas em função do Teorema Central do Limite, que assegura que, independente da distribuição em questão, a distribuição da média amostral se aproximará do modelo normal à medida que o tamanho da amostra aumenta. No entanto, como parte dos pressupostos dos modelos não foi mantida, pede-se cautela na interpretação dos resultados. As comparações pareadas tiveram seu valor de $\mathrm{P}$ ajustado pelo método de Bonferroni. Estipulou-se nível de significância de 0,05 para rejeição da hipótese nula nos testes de hipótese. As análises foram realizadas no software $\mathrm{R} 3.5$, com os pacotes tidyverse (Wickham, 2016), psych (Revelle, 2015) e emmeans (Lenth, 2018).

\section{O trabalho profissional do Serviço Social na Previdência Social}

A partir da Constituição da República Federativa do Brasil (CF/1988), quando da inclusão da PS como parte da Seguridade Social, há um avanço no campo dos direitos sociais, do trabalho, civis, políticos e humanos, inclusive no âmbito da PS, que prevê garantias ao trabalhador rural e 
à agricultura familiar na qualidade de segurado especial, bem como os benefícios socioassistenciais para idosos e deficientes pobres. Contudo, em anos subsequentes à $C F \backslash 1988$, avançaram também as medidas de restrição a esses direitos que tinham acabado de ser garantidos, a exemplo da contrarreforma da PS ocorrida por meio da Emenda Constitucional n. 20, aprovada 1998. Faz-se mister registrar que desde então a PS vem sofrendo intensas contrarreformas ou medidas regressivas de direitos, obstaculizando a efetivação daqueles direitos (Lourenço; Lacaz; Goulart, 2017).

O Serviço Social na Previdência Social (PS) advém desde a década de 1940. Entretanto, na esteira da implantação de medidas neoliberais pelo governo de Fernando Henrique Cardoso (FHC), em meados dos anos de 1990, foi extinto o Serviço Social da estrutura da PS, dentro da prerrogativa de que o Estado deveria financiar o capital, seja por meio das privatizações, seja por meio do fundo público, mas não deveria financiar a força de trabalho. Assim, promoveu amplo e intenso desmantelamento dos direitos sociais, do trabalho e previdenciários, além da reforma do aparelho do Estado.

Considera-se que a extinção do Serviço Social da PS, inclusive da Divisão de Serviço Social em Brasília, impõe condições concretas para o trabalho profissional, pois apesar de os(as) AS permanecerem na PS, tiveram autonomia e importância diminuídas, além da sua rarefação, pois foram inviabilizadas novas contratações, e os(as) que permaneceram ficaram mais subordinados às gerências e respectivas imposições para o exercício de um trabalho muito mais burocratizado e distante do projeto ético-político profissional do Serviço Social e da "Matriz teórico-metodológica do Serviço Social” (Brasil, 1994), que enfatiza o compromisso com os direitos sociais e princípios democráticos.

Com a extinção do Serviço Social previdenciário foram necessárias muitas lutas protagonizadas pelas assistentes sociais que permaneceram na PS e pelos organismos coletivos da profissão alinhados a órgãos diversos da sociedade para que o Serviço Social fosse incluído novamente na 
estrutura do Instituto Nacional de Seguro Social (INSS), o que ocorreu a partir do Decreto n. 5.870/2006 (Braga e Cabral, 2007), justificada, sobretudo, em decorrência da necessidade de avaliação social para o Benefício de Prestação Continuada (BPC). “[...] o maior movimento que destacou a importância do Serviço Social do INSS foi de assistentes sociais internos na Previdência, mas também das entidades que representam a defesa do direito do segurado, do usuário, da pessoa com deficiência, né? [...] (Oficina 3, AS, PS-SP, 2017).

Em 2009, teve aquele concurso grande que recompôs o Serviço Social na Previdência, porque enquanto serviço previdenciário já não existia, pois tinha sido extinto, então as profissionais que ainda permaneciam estavam realocadas em serviços como o PEP, que é de Educação Previdenciária, no serviço Reabilitação Profissional e na coordenação do Benefício de Prestação Continuada (BPC), e algumas também na gestão de pessoas no RH [Recursos Humanos]. Aqui, nessa agência, já não tinha mais nenhuma profissional remanescente. Essa é uma agência que está subordinada à gerência de " $\mathrm{X}$ ", e lá existiam três assistentes sociais dessas remanescentes, sendo que duas atuavam na Reabilitação Profissional e uma na coordenação estadual do BPC, que ficava mais na capital, mas foi quem nos recepcionou, e acabou deixando a coordenação do BPC para assumir a nossa chefia técnica na gerência. Então, assim nós podemos dizer que na gerência "X" e na agência de "X", foi em 2009 que o Serviço Social retornou como um serviço previdenciário, e começou do zero, estruturando o serviço, até a própria estrutura física que não existia, porque não tinha mais espaço para assistente social atuar [...] (Entrevista coletiva, AS, PS-SP, 2018).

Constata-se que foi o concurso público para analista de seguro social, com formação em Serviço Social, ocorrido em 2008, que possibilitou o retorno do Serviço Social para a PS, em 2009, quando já havia rarefação de AS que ainda atuavam na Previdência Social, sendo que na maioria das agências não havia infraestrutura e/ou condições materiais adequadas para o trabalho profissional. 
Evidencia-se que o espaço sócio-ocupacional do Serviço Social na PS é desde sempre um campo de luta para a garantia de direitos. Trata-se de um(a) profissional que atua diretamente na orientação às pessoas, em geral de baixa renda, com poucos anos de escolaridade e também de inserção precária no mercado de trabalho a respeito dos seus possíveis direitos, o que acaba indo na contramão da ideia de seguro tão prevalente no interior da PS e nas diretrizes e normatizações feitas pelos vários governos.

A partir de 2016, o neoliberalismo no Brasil ganhou novo impulso, inclusive com o ajuste fiscal e a criação de amplas medidas para a retirada de direitos e, no que diz respeito ao Serviço Social na PS, novamente foi proposta a sua extinção por meio de minuta que substitui Serviço Social por Avaliação Social.

O impacto foi esse, mudança de diretorias... que impacta na forma como o trabalho é gestado, pensado e autorizado, e impactou que nós perdemos esse cargo, nós perdemos muito a autonomia... Hoje, o que nós sentimos é que, na correlação de força, a perícia médica acabou ganhando mais espaço e mais força, e é uma parcela... porque assim a perícia médica do INSS..., tem uma parcela na perícia médica que tem uma ideologia e outra que tem outra, e essa parcela da perícia que tem uma ideologia mais conservadora é que está no poder agora. Antes quem estava no poder tinha uma visão de até da própria perícia médica no sentido mais multidisciplinar... não era um modelo muito biomédico, defendia mais o modelo biopsicossocial. Hoje, voltou ao poder quem defende mais o modelo biomédico. Isso interfere muito no nosso trabalho, do Serviço Social (Entrevista coletiva, AS, PS-SP, 2018).

Não foi retirado do organograma, a divisão continua lá; em Brasília, estamos subordinados à Diretoria de Saúde do Trabalhador, que tem a Divisão do Serviço Social e a Divisão de Reabilitação Profissional, que está junto da Diretoria de Saúde do Trabalhador. A Divisão de Serviço Social continua existindo no organograma da Previdência, no entanto, não tem mais chefia, não tem uma pessoa e nem um chefe da divisão. Então, na verdade, só 
tem alguns funcionários lá que trabalham no sentido[...]. O que foi tirado do organograma foram as superintendências..., nas superintendências também tinha um cargo dentro da seção de Saúde do trabalhador, que era o representante técnico de Serviço Social. Então, esse cargo foi extinto. $\mathrm{Na}$ verdade, quando passou para o governo Temer, começou um desmonte das diretorias, mudaram as pessoas, os diretores..., quando mudam as pessoas, mudam as ideologias e, aí, começou esse processo de desmonte do Serviço Social, inclusive novamente, neste momento, é um novo processo de desmonte do Serviço Social (Entrevista coletiva, AS, PS-SP, 2018).

Assim, em tempos de agudização do neoliberalismo, a manutenção do Serviço Social previdenciário é um grande desafio, uma vez que as medidas neoliberais adotadas têm sido no sentido de retirar direitos. Em consequência, isso afeta o Serviço Social, em particular por sua atuação estar intimamente relacionada à garantia de direitos.

Há que se considerar também a edição da Medida Provisória n. 871, de 18 de janeiro de 2019 (Brasil, 2019b), recentemente transformada em lei, que trata da permanente avaliação de trabalhadores em afastamentos ou incapacitados.

Se a intenção é corrigir fraudes, certamente, teriam outras medidas, e não a mudança na lei, que visa tão somente reduzir o direito da população, por exemplo, a carência para o salário-maternidade. Antes da Medida, a carência era de dez meses quando a pessoa perdia a qualidade de segurado, ela readquira a qualidade pagando só um terço, e se ela retomasse a qualidade de segurado e cumprisse cinco contribuições, ela já teria o tempo mínimo para solicitar o benefício. Só que agora ela tem que contribuir por dez meses. Isso é para salário-maternidade, auxílio-doença e reclusão (Grupo focal 1, AS, PS-SP, 2019).

A crise do capital tem criado o espaço para uma onda contínua de contrarreformas, que faz da ascensão do neoliberalismo um cenário social próximo ao que Marx estudou e denunciou no século XIX (Marx, 2006). 
Em 2019, a MP n. 905 (Brasil, 2019b) rebaixa ao máximo a contribuição previdenciária e extingue o Serviço Social da PS, bem como extingue direitos trabalhistas e previdenciários.

É importante ter em mente que tais mudanças não são apenas de caráter técnico ou gerencial sem maiores repercussões para o cotidiano das agências, do acesso aos diretos e do trabalho profissional, mas é uma navalha que fere na carne dos cidadãos e cidadãs, incluindo os(as) funcionário(as) públicos como um todo. Esse desmonte traz consequências importantes para a qualidade do serviço prestado e para o trabalho profissional do Serviço Social na PS.

A nosso ver o Serviço Social deveria ser bem mais amplo no sentido do atendimento ao segurado em todos os benefícios em si, principalmente na questão socioeducativa de levar até o cidadão o conhecimento dos seus direitos e deveres, mas isso não ocorre no dia a dia, devido às tarefas administrativas que nos são demandadas e que nem são do Serviço Social, mas a gente acaba tendo que fazer em função também do quadro de funcionários que está cada vez mais se extinguindo. Pra você ter uma ideia, só esse ano vamos perder mais de 11 mil servidores... Vamos perder não, já estamos perdendo devido às aposentadorias que estão ocorrendo (Grupo focal 1, AS, PS-SP, 2019).

Pela análise das entrevistas com as AS da PS é possível sugerir ao menos duas características: 1) a eliminação das superintendências e da referência técnica de Serviço Social no âmbito previdenciário implica a sua maior exposição às gerências, que via de regra desconhecem o trabalho profissional e imputam o fazer mais burocratizado e vinculado ao conceito de seguro social, e não de seguridade social; 2) no bojo da redução dos horizontes no que diz respeito aos direitos previdenciários, há um processo em andamento que empurra parte da classe trabalhadora para a previdência privada e para os que se mantiveram vinculados ao sistema público, propõe-se um sistema enxuto e acessado via serviço on-line. 
Eu vejo assim, nesses seis anos que estou na Previdência, esse é o momento mais crítico que a gente está vivendo em todos os sentidos, e para o Serviço Social, vamos conseguir reinventar ou sobreviver? Há um desmantelamento e não sei até onde vai [sic] os funcionários públicos, enquanto autarquia, porque estamos caminhando para uma extinção, o teletrabalho é um exemplo (Grupo focal 1, AS, PS-SP, 2019).

Em 2019, com a reorganização e a reestruturação das agências da PS, o INSS passou a disponibilizar praticamente a totalidade dos serviços pelo aplicativo Meu INSS ou pelo telefone 135, inclusive todo o envio de documentação passa a ser digitalizado. Também já se encontra em andamento o projeto-piloto para o teletrabalho.

As tecnologias digitais, fundamentadas no computador, software e redes, não são novas, mas estão causando rupturas à terceira revolução industrial; estão se tornando mais sofisticadas e integradas e, consequentemente, transformando a sociedade e a economia global. Por esse motivo, os professores Erik Brynjolfsson e Andrew McAfee do Massachusetts Institute of Technology (MIT) disseram que este período é "a segunda era da máquina" no título do livro publicado por eles em 2014; estes dois professores afirmam que o mundo está em um ponto de inflexão em que o efeito dessas teconolgias digitais irá se manifestar com "força total" por meio da automação e de "coisas sem precedentes" (Schwab, 2016, p. 16).

São mudanças, dentro do espaço possível dos avanços tecnológicos, que de imediato pressupõem a redução de força de trabalho vivo, que no Brasil poderá significar também o fim das agências físicas de PS, além de ampla restrição de acesso, considerando o nível de escolaridade e de conexão na internet vivenciada por ampla maioria da população brasileira. Schwab (2016) alerta para o fato que a $4^{\text {a }}$ RI, pelo seu escopo, profundidade e amplidão, põe em curso ampla e profunda revolução da produção, consumo e da vida em sociedade, tendencialmente marcada por aprofundamento da desigualdade social e da concentração de renda. 
Trata-se de uma revolução digital, mas que não se limita ao sistema de máquinas inteligentes e conectadas, mas congrega três grandes áreas: física, digital e biológica de forma integrada, que a nosso ver fere, sobretudo, o social.

O próximo passo é a biologia sintética. Ela oferecerá a capacidade de criar organismos personalizados, escrevendo o DNA deles. Deixando de lado as profundas questões éticas que isso levanta, esses avanços não só causarão um impacto profundo e imediato na medicina, mas também na agricultura e na produção de biocombustíveis (Schwab, 2016, p. 29).

As principais nações que protagonizam a revolução em curso são Alemanha, Estados Unidos, China e Japão. Esses também são os países que na divisão internacional do trabalho têm e manterão o controle do processo produtivo, das informações/dados e dos rumos econômicos, sociais, biológicos e ético-políticos mundiais (Fernandes, 2019).

No Brasil, a ampla maioria da classe trabalhadora tem baixíssima escolaridade, o que implica dificuldade de acesso aos serviços ofertados pelo sistema on-line, além das dificuldades próprias para a compreensão do funcionamento do sistema, inclusive legal, considerando a rapidez com que as leis mudam e inclusive as regras e normas vigentes na recém-aprovada contrarreforma da PS.

Hoje, a pessoa já não consegue informações de tempo de contribuição na agência, ela tem que fazer no site, no Meu INSS. Agora para ela saber as regras para se aposentar, se ela se enquadra ou não, terá que ler a legislação, ou seja, ela não vai mais receber as orientações no INSS, ela tem que buscar no site. Se é uma pessoa que não consegue ler ou se lê, mas tem dificuldade de compreender, fica complicado; ela terá que saber a legislação (Grupo focal 1, AS, PS-SP, 2019).

Mudanças tecnológicas e de gestão em curso, tais como a possibilidade do teletrabalho e de todo acesso à PS pelo sistema digital no $\mathrm{Meu}$ 
INSS e do E-Social, sendo que esse último sistema permite amplo cruzamento de dados das informações dos segurados. Tais agenciamentos levarão o sistema de PS a uma nova configuração, que, como bem exposto pelo depoimento, caminha para a extinção da autarquia previdenciária, enquanto estrutura física, tal como a conhecemos.

A contrarreforma da PS em curso e a interação do acesso ao sistema via estrutura on-line, por um lado, cria dificuldades das condições materiais e de infraestrutura para o acesso aos direitos e benefícios previdenciários; por outro, há uma interação direta com o trabalho profissional do Serviço Social, que, para operar, enfrenta uma nova mas continua interação de conflitos entre o seu projeto ético-político — pautado na defesa intransigente dos direitos - e uma contraditória imposição de normas explícitas e implícitas, numa estrutura que se assenta no não direito e em um conjunto de disposições de condutas de normas enunciadas pela sua disposição em sistema on-line, que distancia o público usuário das agências e, em consequência, dos diretos. Isso nos leva a imaginar, numa perspectiva crítica, as contradições que a sua efetivação implicaria, não a estabilidade necessariamente, mas a destruição do sistema atual, vale repetir.

No geral, as AS têm relatado pouca autonomia para conduzir o seu trabalho, por exemplo, a imposição da atuação profissional no Programa de Reabilitação Profissional e na análise de processos.

Então, aqui, nós atendíamos aproximadamente 70/75 vagas mensais, e essas vagas eram todas ocupadas, porque a pessoa chega e tem dúvida e quer falar com a assistente social; se tinha horário, agendava. Só que isso vem sendo cortado, porque a gente assumindo a Reabilitação Profissional, essas vagas caíram de 70/75 para quinze vagas mensais. Então, quer dizer você não atende ninguém, quinze vagas é ridículo. Você dizer que uma agência que atende uma população de mais de 500 mil pessoas, porque só da cidade é mais de 300 mil, mas tem o entorno dela, então, ao todo são mais ou menos 500 mil pessoas referenciadas a essa agência. Assim, quinze vagas mensais acabam em uma semana, as pessoas 
ficam sem esse atendimento, o próprio servidor não sabe como orientar as pessoas aqui, e fica naquela: "Vai ter ou não vai ter? O que eu faço?". Simplesmente foi feito desta forma, nós tentamos argumentar tudo isso e nós não conseguimos sequer com a nossa assessoria técnica, que é da área do Serviço Social, que fica na gerência... (Entrevista coletiva, AS, PS-SP, 2018).

Há um sério limite exposto pelas entrevistadas, que é o tempo disponível para o atendimento ao público que demanda informações, que no caso evidenciado, é determinado pela gerência, que fixou em apenas um dia na semana. Outro limite verificado é a inviabilização das atividades de socialização de informações coletivas, que são atividades externas às agências de PS realizadas na rede de serviços, inclusive em penitenciárias. Cabe destacar que durante as entrevistas foram expostas experiências profissionais realizadas pelas AS junto à comunidade, como orientação de benefícios previdenciários nos presídios, sobretudo feminino, quando também procedia a análise de situações específicas, sendo relatado que inúmeras pessoas, apesar de terem o direito de seguradas da PS, não tinham acessado o direito, como o auxílio-reclusão, sendo de fundamental importância a socialização das informações.

Trata-se de um processo fundado na restrição de autonomia profissional, o que fere essencialmente o trabalho criativo e satisfatório, donde se vê nos discursos a frustração com o trabalho.

Comigo se passou o seguinte: teve uma reunião em São Paulo e a chefe de benefício falou: "O trabalho de vocês não aparece... a gente tem um monte de processos represados". Na nossa gerência temos quase mil BPCs, daí o que ela falou: "Todo mundo terá que fazer análise". Todo mundo do Serviço Social, mas não dá para todas fazerem análise, tem assistente social na reabilitação, em outros programas, então, não dá para todas fazerem análises. Só que, aí, tem outro problema: o processo para chegar até a gente tem que ser finalizado pelo administrativo, e se não finaliza não chega até nós. Isso porque o administrativo tem outras prioridades, como 
aposentadorias para fazer, mas se ele não finaliza, a gente não faz. Vou te falar uma coisa: nessa semana inteirinha, hoje é sexta feira, não teve nenhuma avaliação social. Então, aqui na agência nós estamos em duas, daí eu tive que assumir isso, porque de fato não tem avaliação social para as duas, como já falei, tem processos parados, mas o administrativo não finaliza, às vezes tem uma demanda espontânea. Mas, enfim, eu fui para análise, a gente chama de portariada, eu fui portariada. Assim, eu não atendo mais, não tenho mais nenhuma relação com o segurado. Eu chego aqui e vou lá para a retaguarda, comecei agora, só finalizo os processos para que eles possam chegar para o Serviço Social fazer a análise social (Grupo focal 1, AS, PS-SP, 2019).

Um caso que considero sério é a reabilitação. Por exemplo, um motorista que tem, às vezes, um salário bom, mas tem uma baixa escolaridade. Você diz para ele: "Você vai escolher um curso para você mudar de profissão". Mas ele diz: "Quanto tempo eu tenho para isso?". Você diz: “Em seis meses". Daí ele fala: "Mas, pera aí, eu vivi a vida inteira como motorista, eu tenho paixão pela minha profissão". Então, é muito complicado você lidar com isso. Enquanto assistente social, eu me coloco no lugar dele, se me dessem seis meses para mudar de profissão, para onde eu iria correr? Que curso eu faria em seis meses para ficar qualificada para o mercado que é extremamente exigente e cruel? [...] Então, é muito complicado você fazer parte desse processo... (Oficina1, AS, PS-MG, 2016).

Os depoimentos destacam que além da burocratização do trabalho, há também o desvio de função de AS para o trabalho administrativo referido como "portariada" e também a participação no Programa de Reabilitação Profissional, no papel de favorecer a alta de usuários, ou seja, o desligamento da PS. São processos marcados pelo não direito e por relações interpessoais hierárquicas, de mando e ingerência das gerências para o desenvolvimento desse trabalho, muitas vezes, sem diálogos. Consideram-se também as desigualdades sociais e regionais que permeiam as agências, mas também a tradição autoritária e centralizadora do INSS. 
A respeito do nosso trabalho, a gente observa que as exigências para as assistentes sociais é o BPC, é a reabilitação, a LC 142. Aí, você acaba não tendo tempo para fazer a socialização das informações. A gente também acaba estando nessa lógica do adoecimento porque já não nos reconhecemos na nossa atuação. Já não temos como questionar a nossa atuação porque a gente não tem noção do que eles estão discutindo em Brasília. O que chega para gente é uma demanda, que se torna muito difícil resistir porque a resistência tem que ser coletiva. A gente sozinha não dá conta de falar: "Não vou fazer reabilitação"; "Não vou fazer isso", ou me dedicar a real função do Serviço Social... A gente está sendo meio que sucumbido por essa demanda e a gente adoece também. A gente percebe algumas angústias, cada um no seu momento individual sofre as pressões de medo, de angústia e tudo isso (Oficina 2, AS - Previdência Social - MG, 2016).

\section{Perfil das AS da PS e a relação trabalho-saúde-doença}

Cabe destacar algumas características sociodemográficas do grupo amostrado, as quais são expostas de forma sumária, apenas indicando os dados prevalentes. O grupo amostrado é composto por 181 AS, 15,1\% do total de participantes desse estudo, sendo $89 \%$ mulheres, com alta prevalência da autoidentificação heterossexual, e 11\% homens, dos quais $53 \%$ se autoidentificaram como heterossexuais. A partir desse momento, o grupo amostrado será identificado no feminino por constituir a maioria. Em relação à cor, 60,2\% se autodeclararam brancas e 66,3\% afirmaram professar alguma fé/religião, sendo 52\% católicas, 15\% espíritas e 11\% evangélicas. A faixa etária mais frequente foi a de $31-41$ anos $(60,8 \%)$, seguida pela de $42-52$ anos (14,9\%), 20-30 anos (12,2\%), 53-63 (8,3\%) e AS acima dessa idade (3,8\%). Em relação à escolaridade, $79 \%$ fizeram alguma pós-graduação, sendo 61,3\% na modalidade de especialização, $14,4 \%$ mestrado e $3,3 \%$ doutorado.

Mais da metade da amostra (52\%) trabalha trinta horas semanais, com alta prevalência de apenas um vínculo de trabalho. Cerca de metade 
das AS participa do Cress (48,6\%) e 53,6\% são sindicalizadas. Das informações salariais, as participantes com dados válidos apontaram majoritariamente receber de seis a sete salários mínimos mensais (71,1\%). Cabe registrar que o salário é composto na sua maior parte pelas bonificações decorrentes do cumprimento de metas.

Em relação às condições de infraestrutura para realização do trabalho, 82,3\% têm sala individual e 48,6\% indicam que possuem também sala para atividades em grupo. Das participantes, $71,8 \%$ indicam que possuem privacidade para atendimentos e $71,3 \%$ indicam que a mobília é boa/adequada às necessidades. Ainda 97,2\% relatam que possuem acesso a computador e 95,6\% indicam que também têm acesso à internet, sendo que $89,5 \%$ do acesso é restrito. Em relação à interferência no trabalho, $36,7 \%$ afirmam que isso ou não existe ou que existe apenas raramente; para 32,2\% ocorre "às vezes" e 31,1\% afirmam ocorrer interferência no seu trabalho.

Em relação aos valores obtidos pela escala Bem-Estar no Trabalho, na subescala Afetos ${ }^{4}$, no geral os resultados foram baixos e nenhuma característica acessada pela escala teve valor médio igual ou superior à mediana (4). De maneira similar à subescala Afetos, a subescala Competências ${ }^{5}$ também apresenta valores baixos e inferiores à mediana. A imagem 1 apresenta tais resultados.

4 A escala "Bem-Estar Geral no Trabalho - escala de Afetos" possui dez sentimentos, especificamente: insatisfação, insegurança, intranquilidade, impotência, mal-estar, desconfiança, incerteza, confusão, desesperança e dificuldade, que devem ser respondidos com opções entre 1 e 7, numa gradação bipolar entre 1 e 7. Por exemplo, se o participante assinalar valores como "1" ou "2" ao item de "satisfação", isto significa que ele se encontra próximo à insatisfação. Caso marque valores como "6" ou "7", a interpretação é a oposta (Blanch et al., 2010).

5 A escala "Bem-Estar Geral no Trabalho - escala de Competências" possui dez sentimentos, especificamente: insensibilidade, irracionalidade, incompetência, imoralidade, maldade, fracasso, incapacidade, pessimismo ineficiência, inutilidade, que, tal como a subescala Afetos, também devem ser respondidos com opções entre 1 e 7, em relação à "magnitude" que o participante identifica (Blanch et al., 2010). 
Figura 1. Resultados médios dos itens das escalas utilizadas

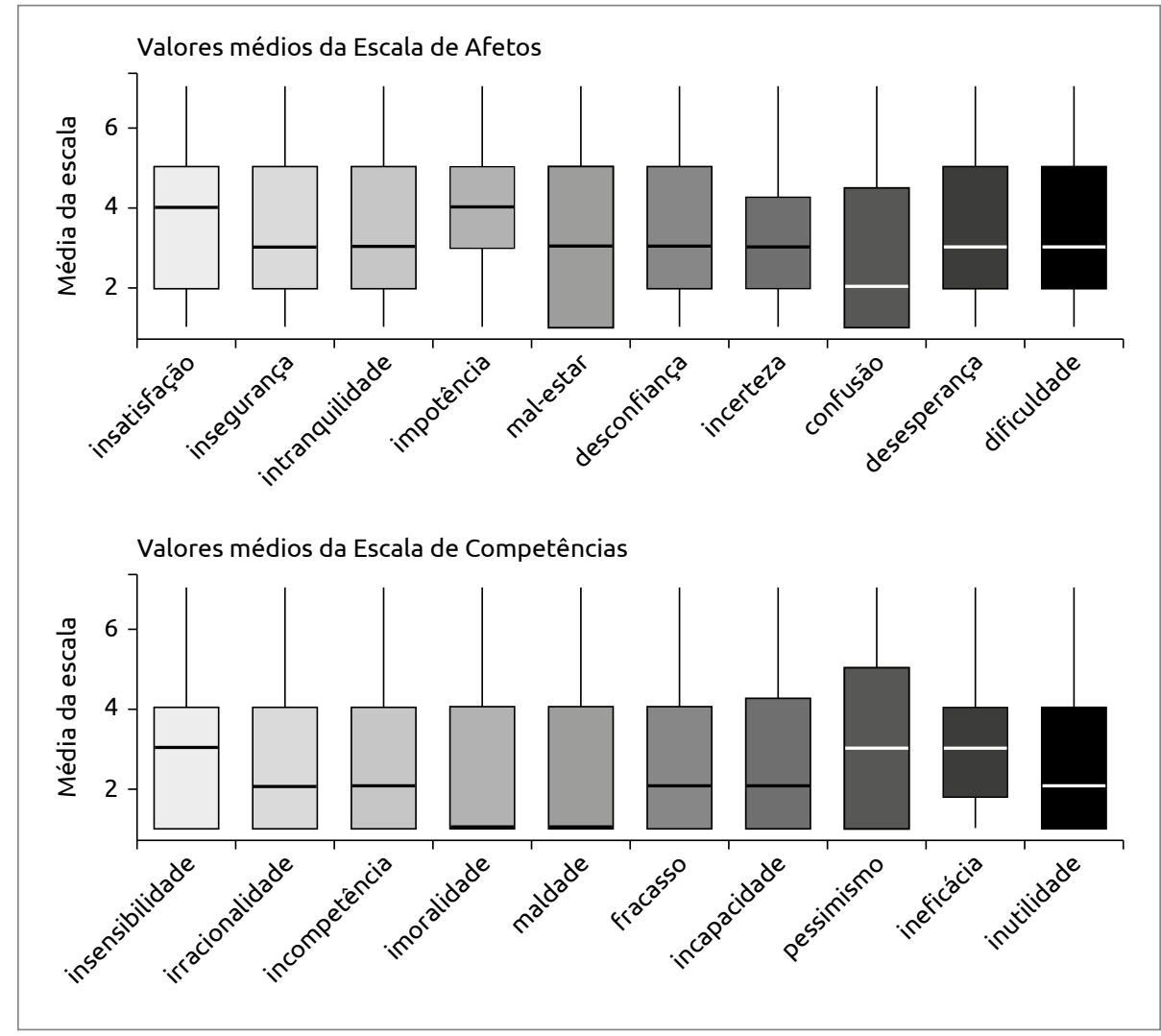

Fonte: coleta de dados empíricos.

Dessa maneira, sugere-se que as AS não vivenciam sentimentos de impotência, mal-estar, insatisfação, entre outros, como também não vivenciam a maldade, o fracasso ou a inutilidade em seu ambiente de trabalho.

Contudo, em direção parcialmente oposta aos resultados obtidos pelas escalas Afetos e Competências, sintomas relacionados a condições adversas de saúde foram frequentes. Por exemplo, os dados apontaram que $86 \%$ das participantes relataram ter cansaço, $83 \%$ algum tipo de ansiedade ou nervosismo e $75 \%$ se sentem tensas. Em outro sentido, relatos de choro com facilidade, tonturas, alteração na voz ou de pressão 
foram pouco frequentes, sendo. todavia, identificados em 38\%, 27\% 17\% e 19\%, respectivamente. É importante alertar que não é possível atribuir essas condições diretamente ao trabalho, dado que os resultados de ambas as escalas sugerem que as AS estão adaptadas em seu ambiente laboral e a análise correlacional apontou uma associação fraca entre as subescala de Afetos e os sintomas de saúde ( $\mathrm{r}=0.28, \mathrm{p}<0.01$ ) e entre a subescala de Competências e os sintomas de saúde $(\mathrm{r}=0.3, \mathrm{p}<0.01)$. A figura 2 expõe tais padrões.

Figura 2. Resultados correlacionais

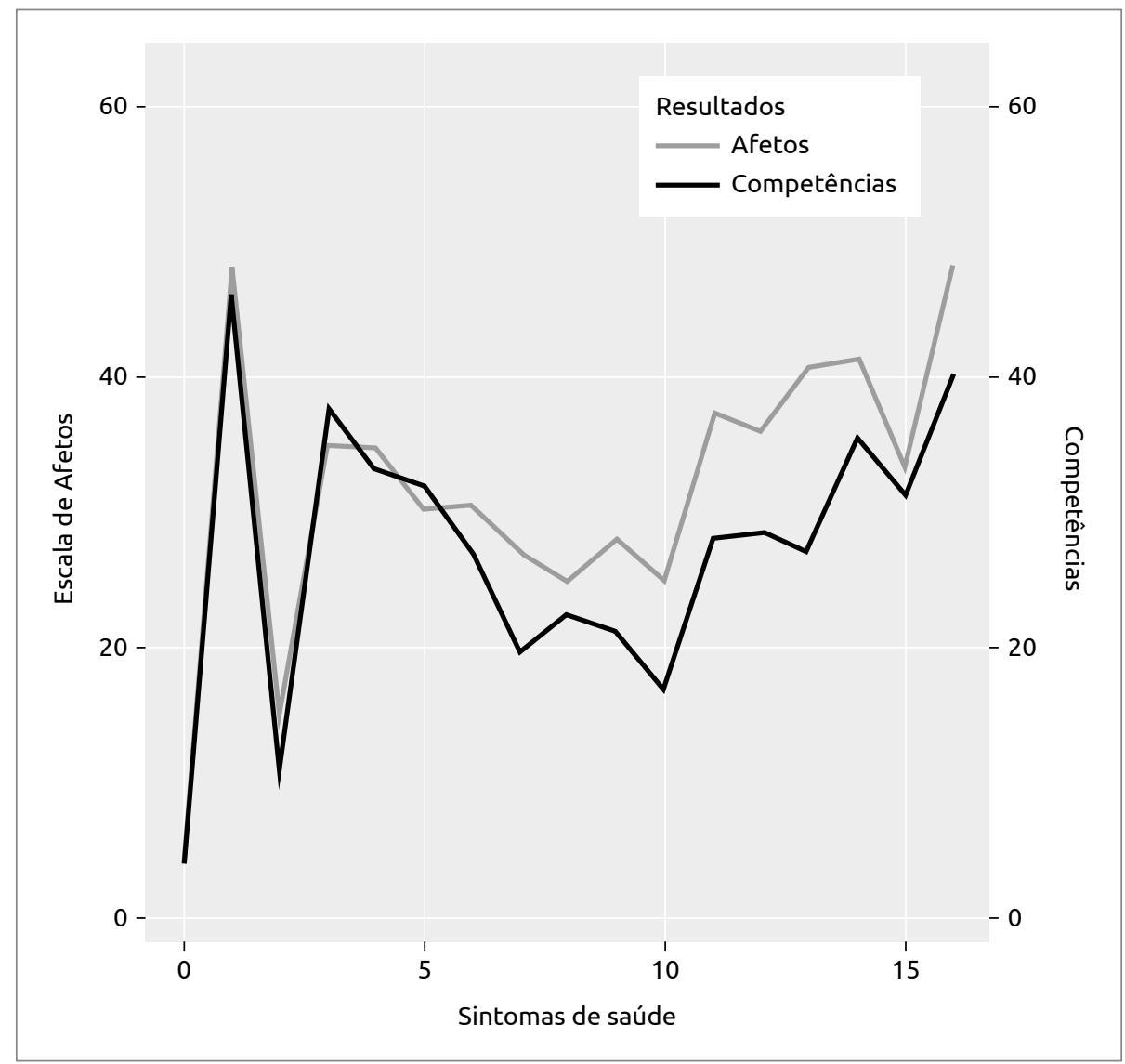

Fonte: coleta de dados empíricos. 
Para investigar o possível efeito da carga horária trabalhada e da faixa etária das AS, utilizou-se uma Anova de uma via. Foi possível concluir que a carga horária não é significativa nem nos resultados da Escala de Afetos $(\mathrm{F}(2,160)=0.82 \mathrm{p}<0.44)$, nem nos resultados obtidos pela Escala de Competências $(F(2,160)=0.89, p=0.41)$. A faixa etária, por sua vez, apesar de não ter efeito significativo na Escala de Competências $(F(3,170)=0.95$, $\mathrm{p}=0.42)$, teve efeito significativo na Escala de Afetos $(\mathrm{F}(3,170)=3.2$, $\mathrm{p}<0.03)$. A comparação pareada permitiu concluir que as participantes entre 53 e 63 anos, quando comparados àquelas com 42 e 52 anos, apresentam menor valor médio $(\delta=-12.6, p=0.04)$ no que diz respeito aos afetos. No entanto, sugere-se cautela na interpretação dos resultados, uma vez que os pressupostos do modelo estatístico não foram plenamente aceitos.

Figura 3. Resultados gerais comparativos

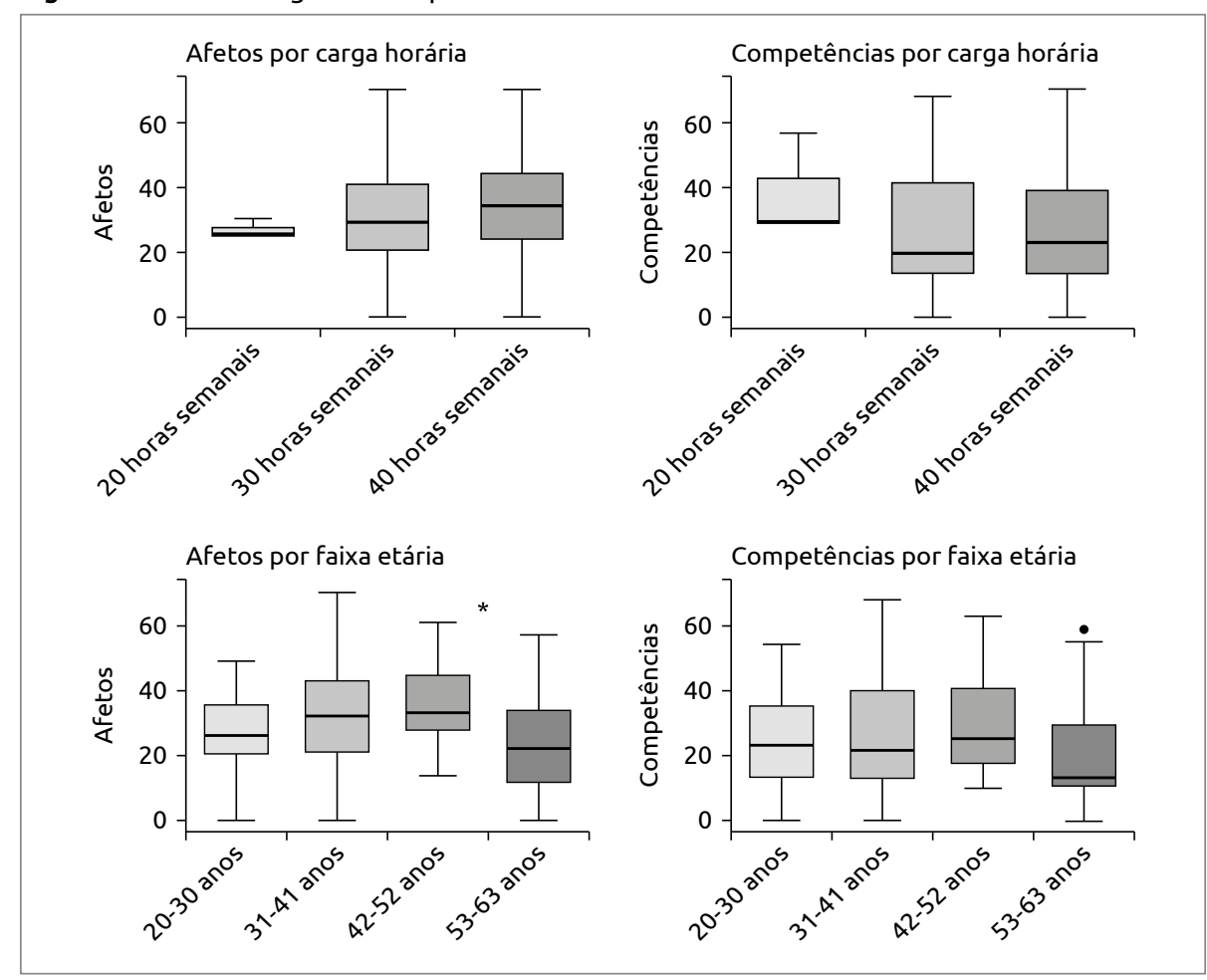

Fonte: coleta de dados empíricos. 


\section{Discussão à guisa de conclusão}

Avaliar fenômenos psicológicos e sociais é uma atividade complexa e que envolve diferentes estratégias. Combinar resultados obtidos por instrumentos padronizados e normatizados com informações mais livres, dinâmicas e detalhadas obtidas por técnicas de entrevistas e GF permite uma maior compreensão do fenômeno estudado, bem como explorar o alcance, as vantagens e as limitações que cada uma das ferramentas científicas possui.

Em relação ao uso parcial da escala de Bem-Estar Geral no Trabalho, especificamente as escala de Afetos e de Competências proposta por Blanch et al. (2010), os resultados indicam que AS não apresentam características negativas em seus afetos, bem como não percebem que o ambiente laboral em que estão inseridos lhe é insensível ou imoral. Nesse sentido, tem-se evidenciado que desvendar os determinantes do processo saúde-doença não prescinde de mensuração estatística, mas também não se deve resumir a essa perspectiva metodológica de pesquisa, uma vez que, para captar a multiplicidade de aspectos objetivos e subjetivos que interagem nesse processo, é preciso uma multiplicidade de técnicas capazes de captar as condições materiais e de infraestrutura de trabalho, mas também as relações interpessoais e os aspectos relacionados à autonomia profissional, bem como reconhecimento, satisfação e realização no e pelo trabalho, que nem sempre comportam em dados numéricos ou cálculos estatísticos. Daí a necessidade da triangulação dos dados, que por meio de várias técnicas, como a coleta de dados estatísticos articulados à coleta de depoimentos, é possível se aproximar da realidade inacabada e contraditória. Assim, do ponto de vista quantitativo, as AS da PS não indicaram notas altas para as escalas de afetos e competências, mas em oposição, os sintomas de prejuízo de saúde são frequentes, apesar de pouco associados às eventuais condições negativas encontradas nas escalas. Todavia, há que se destacar que os depoimentos coletados por meio de entrevistas e grupos focais (GF) e Oficinas sugerem sofrimento no trabalho de AS atuantes na PS. 
A gente deixa de ser assistente social. É isso que angustia, na verdade, o que parece que está posto para o Serviço Social é uma árdua e onipotente tarefa de encontrar tempo, motivação e disposição para reflexionar e contextualizar não só o processo produtivo que adoece, mata e explora, expropria, mas também encontrar alternativas para transformar esses processos em feliz, criativos... Nós temos que repensar o nosso próprio processo de trabalho alienante, infeliz, e tentar fazer dele um trabalho feliz, criativo, um trabalhador social, exatamente, isso que nos é retirado e, por isso, essa angústia toda, esse adoecimento que não é visível, depressão não é visível, até que a gente consiga arrancar um braço e falar: "Eu estou triste, eu quero morrer". Arranco um pedaço de braço, até que consigo acabar de uma vez com isso. Freud diz que há uma intenção, mas não há coragem para acabar com isso de uma vez. Acaba com o tesão do trabalhador (Oficina 1, AS, PS - MG, 2016).

O depoimento mostra o anverso das informações dadas às escalas e obtidas sob análise estatística e evidencia as repercussões psicossociais do trabalho de AS na PS. Evidencia-se a referência a um tipo de sofrimento mudo, invisível e que não se materializa propriamente em uma patologia, mas revela um tipo de morbidez marcada pela angústia e pela luta para transformar o trabalho cotidiano em criativo e bem-feito. Esse caráter fundamental tem incidência nos dados estatísticos, pois a positividade no trabalho pode ser vista mais como o resultado de um esforço vigoroso para transformar as condições atuais de trabalho, e não nas reais condições propriamente ditas.

A interferência da gestão no trabalho profissional ficou em torno de 32\% para interferência, para 31\% isso "às vezes" ocorre e para 32\% essa interferência não ocorre. Todavia, $86 \%$ das participantes relataram ter cansaço, $83 \%$ ansiedade ou nervosismo, $75 \%$ tensão e $38 \%$ relataram chorar com facilidade. No entanto, nenhuma dessas porcentagens foi analisada de forma inferencial.

Ao realizar entrevistas, GF e Oficinas, o conteúdo das informações revelaram que as relações de trabalho mantêm profunda simbiose com 
os sintomas de saúde ora evidenciados, pois há um cansaço generalizado. Durante as entrevistas, pôde-se visualizar um sofrimento que beira a um mal-estar coletivo no trabalho ante a redução das atividades próprias do Serviço Social e mudança do padrão de atividades para aspectos mais burocráticos e inserção no Programa de Reabilitação Profissional, além do convívio com os cortes de benefícios e a iminente destruição do sistema de PS tal como conhecemos. Deve-se também considerar como aspecto de primeira ordem que os resultados estão subordinados ao jogo de forças e interesses fulcrais da gerência, além de determinados pela instituição e mediados pelos fenômenos políticos e econômicos em jogo.

A literatura frequentemente aponta que é esperado que técnicas diferentes gerem resultados diferentes (Bazeley, 2009; DeMaio e Landreth, 2004). Se por um lado a combinação entre todas as técnicas permite explorar as diferentes perspectivas que os participantes trazem durante a coleta de dados; por outro, é possível também que isso seja consequência de direcionamento em ambientes em que interações podem ocorrer, como é o que acontece em entrevistas e GF, onde pode vigorar maior liberdade para a fala e a exposição de problemas, que, de alguma forma, quando analisado individualmente, perde força e, em oposição, em conversa presencial e grupal, pode ocorrer maior encorajamento para dizer como se passa o cotidiano de trabalho, as relações interpessoais nesses espaços, o que se deseja, espera e o que de fato é possível ser feito.

Finalmente, uma vez que o presente trabalho é um recorte de um projeto maior, os resultados são parciais e sua generalização não é recomendada. No entanto, os achados aqui fornecem elementos para a continuidade do debate acerca das condições de trabalho e saúde das AS que atuam na Seguridade Social e, em específico, na PS, bem como identificam questões metodológicas sobre resultados discrepantes que serão futuramente exploradas e debatidas. 


\section{Referências}

ANTUNES, Ricardo. O privilégio da servidão: o novo proletariado de serviço na era digital. São Paulo: Boitempo, 2018.

BAZELEY, Patricia. Integrating data analyses in mixed methods research. Journal of Mixed Methods Research, 2009. Disponível em: https://doi.org/10.1177/1558689809334443. Acesso em: 15 jun. 2019.

BLANCH, J. M. et al. Cuestionario de bienestar laboral general: estructura y propiedades psicométricas. Revista Psicologia Organizações e Trabalho, v. 6, n. 2, p. 157-170, 2010.

BRAGA, Léa; CABRAL, Maria S. R. (orgs.). Serviço Social na Previdência: trajetória, projetos profissionais e saberes. São Paulo: Cortez, 2007.

BRASIL. Medida Provisória n. 905. Institui o Contrato de Trabalho Verde e Amarelo, altera a legislação trabalhista e dá outras providências. 2019a. Disponível em: https://www. legisweb.com.br/legislacao/?id=384681. Acesso em: 22 fev. 2020.

BRASIL. Medida Provisória n. 871, de 18 de janeiro de 2019. Presidência da República. 2019b. Disponível em: http://www.planalto.gov.br/ccivil_03/_Ato2019-2022/2019/Mpv/ mpv871.htm. Acesso em: 15 mar. 2019.

BRASIL. Matriz teórico-metodológico do Serviço na Previdência Social. Ministério da Previdência Social, 1995. Disponível em: http://cresspr.org.br/wp-content/uploads/ arquivos/matrizteoricometodolgicassprevsociall.pdf. Acesso em: 15 mar. 2019.

DEMAIO, Theresa J.; LANDRETH, Ashley. Do Different Cognitive Interview Techniques Produce Different Results? In: PRESSER, Stanley et al. Methods for Testing and Evaluating Survey Questionnaires. Hoboken: John Wiley \& Sons, Inc., 2004. p. 89-108.

FERNANDES, Victor César Rodrigues. A distopia empírica do capitalismo digitalizado: novas formas de controle, reordenamento econômico, político e social no marco da Indústria 4.0. In: SOUZA, Edvânia A.; SILVA, Maria Liduína Oliveira. Trabalho, questão social e Serviço Social: a autofagia do capital. São Paulo: Cortez, 2019. p. 61-73.

GOULART P. M. et al. Questionário de bem-estar no trabalho: estrutura e propriedades psicométricas. Estudos de Psicologia, Campinas, n. 29 (Supl. 1), p. 657-665, 2012.

LENZI, Júlia. Contrarreforma da Previdência Social: entrevista com Júlia Lenzi (USP). Fórum de Saúde do trabalhador e da trabalhadora: Debates e entrevistas. Disponível em: https://www.youtube.com/watch?v=mERDh3CJQds. Acesso em: 15 out. 2019.

LENTH, Russel. Emmeans: Estimated Marginal Means, aka Least-Squares Means. R package version 1.4.5, 2018. Disponível em: https://CRAN.R-project.org/package=emmeans. Acesso em: 12 jun. 2019. 
LOURENÇO, Edvânia Ângela de Souza et al. Condições de trabalho de assistentes sociais da área da saúde e repercussões psicossociais. Saúde e Sociedade, São Paulo, v. 28, n. 1, p. 154-168, 2019. Disponível em: https://doi.org/10.1590/s0104-12902019180675. Acesso em: 12 jun. 2019.

LOURENÇO, Edvânia Ângela de Souza; LACAZ, Francisco Antonio de Castro; GOULART, Patrícia. Crise do capital e o desmonte da Previdência Social no Brasil. Serviço Social \& Sociedade, São Paulo, n. 130, p. 467-486, set./dez. 2017. Disponível em: http://www.scielo. br/pdf/sssoc/n130/0101-6628-sssoc-130-0467.pdf. Acesso em: 15 mar. 2019.

MARX, Karl. O capital: crítica da economia política: livro I. 23. ed. Rio de Janeiro: Civilização Brasileira, 2006.

REVELLE, William. Package "psych" - Procedures for Psychological, Psychometric and Personality Research. R Package, 1-358. 2015.

SCHWAB, Klaus. A Quarta Revolução Industrial. 1. ed. Trad.: Daniel Moreira Miranda. São Paulo: Edipro, 2016.

SOUZA. Edvânia Ângela de. Cipoal da Insegurança Imagem perfeita do trabalho no século XXI. Visat Multiplicadores em Saúde do Trabalhador. Out. 2019. Disponível em: https:/www.multiplicadoresdevisat.com/artigos-de-outubro-a-dezembro-de-20. Acesso em: 15 out. 2019.

SOUZA. Edvânia Ângela de; SILVA, Maria Liduína Oliveira. Cipoal da insegurança: capitalismo flexível, neoliberalismo e as condições de trabalho de assistentes sociais que atuam na Seguridade Social no Brasil. In: SOUZA. Edvânia Ângela de; SILVA, Maria Liduína Oliveira (orgs.). Trabalho, questão social e Serviço Social: a autofagia do capital. São Paulo: Cortez, 2019. p. 221-248.

VIANA, Silvia. Rituais de sofrimento. São Paulo: Boitempo, 2012.

WICKHAM, Hadley. Tidyverse: Easily Install and Load “Tidyverse” Packages. R package version 1.0.0, 2016.

\section{Sobre os autores}

Edvânia Ângela de Souza - Professora de Serviço Social.

E-mail: edvaniaangela@hotmail.com

Luís AnUnCiação - Professor do Departamento de Psicologia.

E-mail: luisfca@gmail.com 